\title{
Romance sob censura
}

Letícia Malard

$U F M G$

Resumo: Interpretação de aspectos de alguns romances brasileiros publicados durante o regime de 1964 para revelar que a tematização de questôes sociopolíticas não criou problemas com a censura porque os escritores lançaram mão de recursos capazes de ludibriá-la.

Palavras-chave: romance brasileiro, ditadura militar, censura.

\begin{abstract}
"Esse choque violento entre o espírito dinâmico da mentalidade atual brasileira e o espírito estático e reacionário das estruturas político-sociais, por obra e desgraça de uma constante censura do pensamento e da expressão, está ameaçando a cultura nacional de uma estagnação ou de um retrocesso, que serão ambos a maior decepção das novas gerações e a própria vergonha da nossa história intelectual."

(Mensagem de Alceu Amoroso Lima ao Ciclo de Debates do Teatro Casa Grande - sessão sobre Literatura. Rio, 19 de maio de 1975).
\end{abstract}

A temporada de caça às bruxas, interrompida no Brasil com a queda da ditadura Vargas em 1945, reabriu-se no primeiro de abril de 1964 com igual ou maior pompa. Se, num primeiro momento, os caçadores se contentaram com atirar nos políticos que sustentavam o governo de Goulart, constituído na legalidade, as suas armas se voltaram em seguida para os que corriam livremente pelos campos 
da cultura e das artes, em especial da literatura. O cortejo dos caçadores, quase sempre em grande aparato e soprando trombetas tonitruantes, embrenhava-se sem cerimônia pelo bosque das editoras, livrarias, teatros e bibliotecas, na sádica expectativa de abater animais tidos como nobres no esporte. Adestrados às pressas para a função, os homens vasculhavam os mais recônditos esconderijos, viam e ouviam o inexistente, destratavam guardas florestais. Enfim, espalhavam o pânico na floresta artístico-cultural tropicalista.

Não podiam regressar à corte de mãos vazias, de armas sem bagagem, expedição quixotesca. E, no jogo do vale tudo para mostrar serviço, mesmo incompetente, não raro caçavam gato por lebre. Uma das caçadas mais famosas aconteceu em setembro de 1965, na Editora Civilização Brasileira. ${ }^{1}$ Além de algumas lebres por conta de Marx e Engels, arrebanhou-se este saco de gatos: um romance do ex-secretário da embaixada de Israel no Brasil, Pinchas Lapide, cujo tema é o conflito entre árabes e judeus na Palestina. Nada de esquerdismo, muito menos comunismo. Título: O canhão e a foice. Ilustração de capa: uma foice. A falta do martelo seria despiste, tal como no aeroporto de Brasília? Outro gatão: um livro da jornalista Leda Barreto - reportagem sociológica sobre questões nordestinas. Com a infelicidade de trazer no título o nome de um dos mais caçados, arquiteto das Ligas Camponesas: Julião, Nordeste e Revolução.

De outros gatos não ficou o atestado de caça. Apenas estórias que corriam de boca em boca, sussurros de inconfidência mineira, de censura brava: $O$ portão vermelho, romance água-com-açúcar de Lin Yutang. Vermelho e chinês. Nosso homem em Havana, ficção do conservador católico Graham Greene, também autor de Oamericano tranquilo. Havana - signo proibido em qualquer significado: cor, charuto, capital.

No cerrado da ficção nacional o quadro da caçada era o mesmo. M. Cavalcanti Proença refere-se ao fato de os censores estarem "espiolhando palavrões, investindo contra textos de Mário de Andrade, José Lins do Rego e Jorge Amado." Da precária análise semiológica de títulos e ilustrações a juízos de falso moralismo era um passo em falso na tocaia da presa. E esses autores desapareceram das livrarias por algum tempo.

1. Cf. Mandado de segurança impetrado pela Editora Civilização Brasileira, p. 411-414.

2. Cf. PROENÇA. A dissemântica de abril, p. 10. 
Em dezembro de 1966, Stanislaw Ponte Preta conseguia verdadeiro milagre. Burlar a censura e lançar o seu volume de bem humoradas crônicas sobre o febeapá. ${ }^{3}$ Como encarte, vinha um diploma a ser preenchido pelo leitor e enviado a alguém que estivesse prestando "relevantes serviços ao subdesenvolvimento cultural do País", citando dele uma frase, tipo das que ilustravam a capa do volume: do Ministro Juraci Magalhães: "O que é bom para os Estados Unidos é bom para o Brasil". Do deputado Lourival Pereira da Silva, contra a minissaia: "Ninguém levantará a saia da Mulher Mineira". De um secretário de segurança do Nordeste, ao proibir a peça Joana em flor, de Reinaldo Jardim, e prender o elenco da peça: "Em Sergipe quem entende de teatro é a polícia”. É ainda Ponte Preta quem nos passa informações estarrecedoras sobre essas caçadas: agentes do DOPS vão ao Teatro Municipal de São Paulo para prender o autor de Eletra (406 AC) por subversão. Em Porto Alegre são apreendidos nas livrarias todos os livros considerados pornográficos, exceto $O$ amante de Lady Chatterley. Justificativa do agente policial: Recebera ordens de tirar das livrarias apenas a pornografia nacional. Em Belo Horizonte, a censura substituía a palavra prostituta por mulher de vida fácil, na peça Liberdade, liberdade, de Millor Fernandes e Flávio Rangel. Comentário de Ponte Preta: "Na atual conjuntura, nos parece um tanto difícil. Ninguém mais tá levando vida fácil”. (p.28)

Ora, esse estado de coisas perdurou por cerca de dez anos, e a nobreza caracterizadora do esporte da caça se transformou nas mais ridículas estórias de humor, descaso e achincalhe da cultura nacional. O lado triste dessa parafernália não poderia deixar de refletir-se na censura política sobre a criação. A recolha indiscriminada de livros em livrarias e bibliotecas - públicas e particulares, a falta de informações e os boatos resultavam em desânimo para os escritores que procuravam uma saída na alegoria, no fantástico e na reportagem policial. É o que observa Silviano Santiago, em balanço sobre a repressão e censura na década de 70:

(...) houve dois tipos de livros que tiveram êxito durante o período: textos que se filiam ao realismo dito mágico e que, através de um discurso metafórico e de lógica onírica, pretendem, crítica e mascaradamente, dramatizar situações passíveis de censura, e os romances-reportagem, cuja intenção fundamental é a de desficcionalizar o texto literário e com isso influir, com contundência, no processo de revelação do real. ${ }^{4}$

3. PONTE PRETA. O festival de besteira que assola o país.

4. SANTIAGO. Repressão e censura no campo das artes na década de 70, p. 52 . 
Pretende-se fazer aqui um inventário pequeno de romances pós-64, extraindo deles elementos que remetem a situações sociopolíticas concretas, porém dramatizadas de tal forma que se viram aptos a driblar os censores. Sustentou-se, assim, o compromisso do escritor com o seu tempo, com a necessidade de fazer do seu texto uma denúncia, um reconhecimento crítico das agruras e contradições do momento histórico. Sem perder o caráter de bons textos literários.

\section{II}

Em 1965 Érico Veríssimo publicava O senhor embaixador, em época de significativa efervescência política na América Latina, de represálias a governantes e diplomatas por questões políticas, em diversas partes do mundo. Lembre-se de que o romance se passa em Sacramento, imaginário país do Caribe, um dos quintais norte-americanos que aspiram à independência. Veríssimo mostra como se dá o domínio lento e gradativo dos Estados Unidos no país, onde grandes empresas se estabelecem para a exploração e exportação de matérias-primas, e as consequências político-sociais disso. Entre elas, o controle indireto da empresa por grupos econômicos e a pressão que exercem sobre o Congresso. Outras questões são levantadas: o golpe militar sob a justificativa de ameaça do comunismo, as ações terroristas de direita, o fechamento do Congresso, as prisões e torturas. Nesse sentido, o Sacramento representa uma alegoria dos países latino-americanos, inclusive o Brasil.

A presença do Brasil como personagem pode ser tomada como técnica de despiste de uma das fatias do real a que o texto remete. Essa presença limita-se praticamente a referências esparsas, como por exemplo a tentativa de um golpe comunista em 1935, a importação de feijão podre duma firma estadunidense cuja falta de idoneidade é descoberta pelo embaixador brasileiro no Sacramento. O romance de Veríssimo conduz os guerrilheiros esquerdistas à vitória e, nesse aspecto, o Sacramento acena para a vitória de Fidel em Cuba.

Esse romance articula basicamente duas vertentes históricas: de um lado, as influências e interferências norte-americanas na América Latina; de outro, as reações locais a tal estado de coisas. Da parte de ditadores que, funcionando como testas de ferro do imperialismo, alcançam o poder, ou através da continuidade de uma oligarquia que nele se instalou durante várias décadas e cujos membros se substituem por herança familiar, ou mediante golpes de Estado. Da parte de líderes 
revolucionários que tentaram libertar o país do jugo desses ditadores, instalando nele um novo sistema político anti-imperialista ferrenho, de olhos voltados para o Leste europeu, ou um regime contemporizador-capitalista porém direcionado para o nacionalismo de onerosas concessões aos Estados Unidos.

Ora, na voz do intelectual desse romance perpassa a ideologia do autêntico liberal democrático-nacionalista, cujo lema é ser contra as ditaduras, tanto de esquerda quanto de direita, voz que reflete de certa maneira a posição de Veríssimo, revelada dez anos depois de publicado o romance: em carta a Daniel Fresnot diz acreditar no imperialismo americano (que antes lhe parecia um tanto inventado pelos comunistas) e também no imperialismo soviético (que os comunistas não querem ver).

Assim entendemos que a "neutralidade" de O senhor embaixador, a não expressão de posições políticas subversivas ou avaliadoras do caso brasileiro e sua substituição estratégica por um caso na América Central, podendo ser metáfora tanto do Haiti quanto de Cuba, contribuíram com a circulação, sem problemas, do romance. A estratégia patenteia-se no nível do discurso literário, numa ambiguidade desorientante para os pouco avisados: a República do Sacramento não é o Brasil, mas qualquer país da América Latina, nela incluído o Brasil, e os acontecimentos poderiam suceder tanto aqui como em outros lugares, dando-se ao 64 um caráter de ano-móvel no calendário das rebeliões latino-americanas. Quando a História os tipificava como brasileiros, o narrador os transformava em arquétipos latinoamericanos e estrategicamente aconselhava às personagens: deixem o Brasil em paz. Lavavam-se as mãos limpando-se a editoração.

O primeiro romance de Jorge Amado pós-64 frustrou àqueles que esperavam um texto político - ainda que no apelo ao alegórico ou ao fantástico em volta engajada à primeira fase do escritor. Dona Flor e seus dois maridos (1966) continua a linha inaugurada com Gabriela cravo e canela (1958), que se afasta da inspiração do realismo socialista - decorrência natural do enfrentamento político-partidário do autor com o PCB na década de 50. Romance de costumes, Dona Flor trabalha o fantástico, sim, mas sem operacionalizar qualquer categoria

5. FRESNOT. O pensamento político de Érico Veríssimo, p. 55. Flávio Loureiro Chaves observa que "A substituição dos extremos direita/esquerda, fascismo/comunismo em O Senhor Embaixador é simplesmente a mudança dos agentes da violência e do totalitarismo, que permanecem imutáveis na essência traduzindo, assim, a imutabilidade da Engrenagem". (Érico Veríssimo: realismo e sociedade, p. 133). 
política no sentido estrito do termo. O plano, agora, reorganiza-se em função de uma fantasia moral ou moralizante nas linhas mestras do romance picaresco, explorando o sincretismo religioso e o eterno maniqueísmo metaforizado na luta entre o espírito e a matéria.

Apesar da predominância de uma época bem definida - época áurea dos cassinos e castelos na cidade da Bahia - o texto trabalha alguns anacronismos indicadores do período de que estamos tratando: assim, o discurso sobre a morte de Vadinho, criado pelos representantes das classes conservadoras, faz calar o anárquico e dissolvente panegírico da ralé subversiva que tenta solapar os costumes e o regime. O qualificador subversivo, frequentíssimo no discurso do regime de 64, aparece no romance aplicado ao padre membro da igreja progressista e aos programas da Rádio de Moscou. As emissoras estrangeiras, sobretudo as dos países socialistas, eram as únicas vozes que se levantavam contra o nosso sistema de governo, atacando "los gorillas del Brasil", irritando as autoridades impotentes diante do fato.

Em algumas rádios trabalhavam exilados, que criticavam o regime em alto e bom português nas programações especiais para o Brasil. E quando o quadro político enegreceu ainda mais, era comum a sintonização de tais emissoras com a ansiedade de se obterem notícias do país que não eram veiculadas dentro dele. Amado fala também de violência fascista contra a juventude, a propósito de censura a um filme francês considerado pornográfico, na época em que o moralismo chegava ao ridículo de proibir a minissaia, como vimos. O aprofundamento das questões morais no romance se esgota no penúltimo capítulo - derradeiro enterro de Vadinho - quando as duas facções se defrontam, a conservadora e a progressista. O narrador remete mais uma vez à questão brasileira, transformando o herói romanesco em herói nacional, e o texto num discurso prenunciador do que a nação almejava:

Vinha o povo correndo nas ladeiras, com lanças de petróleo e um calendário de greves e revoltas. Ao chegar na praça queimou a ditadura como um papel sujo e acendeu a liberdade em cada esquina. ${ }^{6}$

Em 1967 saem dois romances inspirados no movimento de 64: $O$ simples coronel Madureira, de Marques Rebelo, e A hora dos ruminantes, de J. J. Veiga. O título do primeiro, afoito para o momento em que atos e figuras militares

6. AMADO. Dona Flor e seus dois maridos, p. 494. 
eram intocáveis, poderia despertar suspeitas quanto a essa intocabilidade. Contudo a narrativa limita-se à apresentação de fatos "revolucionários" sem maiores pretensões de análise política ou de espírito crítico de suas personagens. Madureira, um militar que apenas cumpre ordens profissionais e deveres domésticos, compõe uma junta interventora numa repartição pública dada como subversiva e corrupta. O material apreendido é decepcionante: duvidosas provas de subversão e nenhuma de corrupção. E Madureira, homem simples e simplório, mais preocupado com o cotidiano de sua vida suburbana e com a imagem a manter perante os superiores, transita como marionete entre o humor e a ironia da estória, sem fazer história.

O caráter linear da narrativa rebeliana, a transparência da linguagem que apenas reduplica o real pouco questionado e questionável, a força do diálogo banalizador de situações que não devem merecer reflexão crítica são elementos compatíveis com a configuração desse anti-herói revolucionário de 64, dividido entre o lar e a caserna, a esposa e a secretária, entre a burocracia anticomunista sherlockiana, para a qual fora inapelavelmente designado, e o quintal de sua casa, com os vegetais e os galináceos queridos. A situação vencedora é o status quo, o lugar da subordinação, da disciplina e da obediência. Assim, a sua ordem, a ordem da sua. casa, a ordem da sua vida... frase final do romance, é a metáfora da nova ordem que se estabeleceu no País.

Uma leitura política de $A$ bora dos ruminantes, também de 67, vai revelá-lo como alegoria do 64 . Os pacatos habitantes da cidadezinha de Manarairema, invadida sucessivamente por misteriosos desconhecidos que neles soltam os seus cachorros e seus bois, são vítimas da violência e da opressão que acabam por dividi-los em dois grandes grupos submissos aos invasores: o dos informantes e o dos depoentes, vivendo em função dos Homens, ou seja, os tiras/militares invasores. Uma ligação possível com o realismo socialista do Leste europeu que poderia ser encontrada nos romances de Veríssimo - pela temática - e de Rebelo - pela transparência da língua literária em face do real - aqui é feita com o realismo mágico, que grassava na literatura latino-americana. Mas, como o romance citado de Veríssimo, o referente textual ultrapassa os limites brasileiros, para alcançar a latino-americanidade como vítima do capitalismo de monopólio e suas consequências político-sociais.

As personagens de A hora dos ruminantes são cooptadas pela ideologia exploratória dos invasores: O carroceiro Geminiano é o primeiro a entrar em contacto com eles. Presta-lhes serviços à medida que vai entristecendo-se e, no fim, sabe-se que nada lhe pagavam. Amâncio, o dono da venda, tem negócio 
com os homens, em cega obediência e profunda melancolia. Paulo Afonso, alienado em seu amor, segue-os sem qualquer tipo de reflexão e por eles é tratado como animal. A moça Nazaré é violentada, o ferreiro Apolinário resiste às ordens e por isso é submetido a interrogatório, provocando a invasão dos bois. A ausência de conscientização político-ideológica das figuras romanescas constitui-se em causa principal de sua cooptação. Esta vai sendo percebida aos poucos, mas em nível despolitizado. O entendimento de que os estranhos são maus e opressores manifesta-se no arrepender-se da colaboração, no desaparecer do medo de quem já foi preso e no sono, por cansaço (da opressão) como mecanismo de fuga. Também aqui poucos são os índices narrativos que remetem a uma situação referencial concreta: militares dando ordens a civis fora do contexto da caserna, interrogatórios policiais gratuitos, olheiros vasculhando a privacidade das pessoas.

Dois romances marcam o primeiro ano da década de 70: Veríssimo retorna com Incidente em Antares e Callado com Bar Don Juan. O retorno de Veríssimo se dá no mais negro período da ditadura militar e, em consequência disso, a melhor saída para o aprofundamento das reflexões políticas no espaço literário é o fantástico, como já tivera Veiga. As duas vertentes históricas trabalhadas em simultaneidade n' O senhor embaixador, num contexto geral de América Latina, agora são articuladas em sucessividade num espaço exclusivamente brasileiro: Antares é uma cidade riograndense, o Rio Grande do Sul é também o Brasil. O 64 é o divisor de águas no romance: "Antares", a primeira parte, possui elevado índice de redundância referencial, não só em relação ao discurso histórico como também ao literário de O tempo e o vento. O incidente - a "ressurreição" de pessoas-símbolo da sociedade antarense durante uma greve que impediria o seu reenterro - é a segunda parte. Literariza-se o pós-64 pelo artifício do fantástico, em especial do rito mágico, numa releitura do J. Veiga de quatro anos antes. Ainda no terreno do fantástico, a realidade e a ficção romanesca são postas em termos de uma visão de classe, relendo-se aqui o Amado de Tenda dos milagres, publicado havia dois anos.

Então pode-se dizer que a literarização do 64 se dá, neste novo Veríssimo, de forma mais sofisticada, porque através da mediação do ritual mágico e do confronto de discursos marcados pela condição de classe, nos limites desse

7. Para uma compreensão política do Incidente é indispensável a leitura de FONSECA, Maria Nazareth Soares. A relação história/estória em Incidente em Antares. 
ritual. A conversa entre vivos e mortos e a de cada um desses grupos no seu próprio espaço fazem emergir assuntos proibidos no referente contextual. O diálogo entre eles e seus desdobramentos, isto é, a mudança comportamental dos vivos e a obrigação de se dizerem ou descobrirem a verdade, equaciona em última instância a desmoralização da burguesia. A recorrência ao fantástico foi a melhor saída literária rentável e infensa à censura para esse equacionamento.

Ressuscitando, os mortos subvertem a ciência, a todo o aparelhamento ideológico e a própria literatura. Essa subversão generalizada permite o afloramento do saber e do poder ilimitados, a vitória da realidade sobre a ideologia, a desestabilização da literatura como mimese. Contra essa subversão a luta dos vivos é vã, pois os mortos vivem no resguardo de sua condição de mortos, isto é, não são matáveis. Eles revivem para falar e agir sobre a falsa consciência, percorrendo o texto romanesco para romper a sua lógica, a sua sanidade e a sua capacidade de remissão a um realismo palpável. Somente desse ângulo é possível compreender, acreditamos, a "Nota do Autor", que abre o romance:

Neste romance as personagens e localidades imaginárias aparecem disfarçadas sob nomes fictícios, ao passo que as pessoas e os lugares que na realidade existem ou existiram, são designados pelos seus nomes verdadeiros.

Aliados à fala do autor-narrador, superpõem-se as de duas personagens. Uma, ideológica, depois que os mortos voltam à sepultura, a seu não-lugar, e os vivos recuperam o lugar da ideologia, negando o incidente. Tenta-se explicar o ocorrido via literatura como ficção de ficção:

A coisa toda não passou da paródia dum conto gótico...

A outra fala, contraideológica, justifica-o pelas relações de produção:

No sistema capitalista, meu amigo, todos os absurdos são possíveis. (p.453)

Em Bar Don Juan, se não fosse a ausência de perspectiva temporal em relação aos fatos - exigência para quem faz História - encontrar-se-ia o romance histórico da Revolução Brasileira, tal como concebida por uma parcela da

8. VERÍSSIMO. Incidente em Antares, p. 454. 
intelectualidade carioca frequentadora de Ipanema. O autor oscila entre a História e a boa reportagem, entre realidade e imaginação, na tentativa de recuperar através da literatura o que era vedado à imprensa. Na condição de jornalista bem informado e tomado de espírito crítico sobre o que acontecia a seu redor, Callado faz um romance de observação irônica da vida e obra dos jovens intelectuais revolucionários de então, um deles escritor. Se, no primeiro momento, a censura tentou impedir a circulação do livro, aumentando com isso a curiosidade dos leitores que já conheciam o politicismo de Callado no Quarup, a liberação posterior trouxe um saldo positivo, tanto para leitores quanto para censores. Os leitores puderam conhecer, via literatura, o que se passava na vida política clandestina do País, inclusive a possível e provável visita de Guevara a São Paulo. Os censores não tinham como censurar um texto que, sob sua ótica, revelava a impossibilidade de qualquer movimento contestador do regime e punia severamente àqueles que o tentassem.

O romance de Callado é o da desilusão revolucionária, fracasso político dos que estavam dispostos a reagir contra o 64, fazendo a verdadeira revolução. As personagens não conseguem livrar-se da sua condição de classe burguesa; perpassamnas as ações individualistas e inconsequentes, a falta de disciplina em contraposição ao alto nível de organização institucional-militar dos que mantêm o poder. E, devido à condição de intelectual pequeno-burguês, elas não têm claro o tipo de socialismo que desejam para o País nem sabem como conduzir o processo revolucionário. Daí Gil, o criador do romance da revolução, afirmar que "Pode-se fazer ficção de quase tudo, mas inventar uma revolução é impossível".

A frustração dos militantes de esquerda é compatível com o próprio sonho revolucionário que se quer transformar em realidade sem instrumentais seguros de ação, ou seja, a participação das massas. No entanto, quando não há lugar no processo histórico para essa participação, como foi o caso brasileiro, outras alternativas são viáveis, mas a sua precariedade cedo se revela. Esta, transformada em derrota, reforça a ideologia por um lado e reorganiza a contraideologia por outro, em recorte ao conceito gramsciano de bloco histórico.

Os estranhos invasores deste mesmo planeta que oprimiram os habitantes de Manarairema regressam configurados mais concretamente em Sombras de reis barbudos, que J. Veiga publica em 1972. Dir-se-ia que a cidade que uma Companhia vai gradativamente oprimindo, com cachorros e bois, no romance anterior, com muros e urubus neste romance, é o mesmo espaço, porém

9. CALlADO. Bar Don Juan, p. 122. 
modernizado em termos de desenvolvimento capitalista. Recordemos a profissão das personagens do primeiro romance de Veiga: carroceiro, vendeiro e ferreiro que trabalham para Os Homens. Ocupações típicas de uma infraestrutura econômica não industrializada ou de baixo índice de industrialização. Esta segunda narrativa já introduz mudanças sociais típicas no desenvolvimento das relações de produção, a começar pelo narrador, uma criança adestrada, formada e conformada pelos valores ideológicos que a Companhia impõe, corporificando em sua narrativa os valores da sociedade militarizada capitalista: o encanto diante do modelo automobilístico, da fotografia, para não dizer da limpeza da farda e do brilho de seus galões. As personagens centrais são funcionários da Companhia e, cooptados, conhecem a prosperidade antes da decadência.

Se em $A$ hora dos ruminantes os estranhos saem tão misteriosos como chegaram, agora eles retornam para ficar, em metáfora do projeto de 64: tímido, na primeira hora, visando à tomada do poder para devolvê-lo aos civis depois de pôr a casa em ordem; ousado, nas horas subsequentes, em retrocesso da intenção inicial pelo aperfeiçoamento da manutenção do poder, alijando-se dele, sempre com maior fôlego, a sociedade civil, à custa de prisões, cassações, controle dos meios de comunicação, censura às artes e deixando o campo livre ao capital estrangeiro. Os moradores da tapera são substituídos pelos senhores da CIA, como Veiga designa a Companhia opressora. O voo dos homens, ao final da narrativa, é congruente com a ressurreição em Antares. Os mortos voltam à sepultura depois de desmascararem a ideologia. Os voadores só voltarão para a festa dos reis barbudos, quando a Cia for destruída e os batistas que ela sustenta caírem do poder.

O fracasso da Revolução é trabalhado também por Moacyr Scliar em O exército de um homem só (1973), nos limites da fantasticidade. Seu anti-herói, o Capitão Birobidjan, tenta realizar o sonho de construir uma colônia socialista com o auxílio de animais, numa rigorosa divisão de tarefas. Entretanto, os seres humanos não lhe permitem levar avante o trabalho, que se desenvolvia a duras penas, e incendeiam a colônia. O romance caminha em duas vertentes que se entrecruzam - o fantástico e a loucura - espaços da transgressão ideológica e, consequentemente, da exclusão social.

O romance de Scliar dialoga com os anteriores na medida em que equaciona o problema da revolução que não deu certo, não só por falta de condições históricas para sua efetivação, como também e principalmente pela origem pequeno-burguesa de seus líderes, que transitam inseguramente entre as posições das diferentes classes sociais sem assumir concretamente a da classe revolucionária. 
Esse Capitão, ao ver-se derrotado no estabelecimento de sua colônia, torna-se um empresário bem sucedido. Mas a revolução está dentro dele. Abandona tudo e retoma-a para morrer cercado pela polícia, em luta inglória.

Os sinos da agonia, de Autran Dourado, vem à luz em 1974 e, curiosamente, precedido de uma "Nota dos Editores" indicando pistas para sua análise e interpretação, nota essa retirada posteriormente. Nela se insiste em três pontos: remissão aos trágicos do passado articulados à decadência de Minas Gerais, esgotado o ouro no século XVIII; negativa de ser ele um romance histórico-realista com anacronismos a serem desvendados pelo leitor; afirmativa de ser um romance moderno pela técnica. Ora, tais explicações, inusitadas nesse tipo de publicação, a meu ver intentam assegurar a circulação do livro, a perigo de leituras inconvenientes para o sistema. Se a "Nota" de fato garantiu a permanência do romance nas livrarias, ela não o livrou de análises que detectassem alegorias não só ao 64 mas também a outras agruras por que passou o Brasil. ${ }^{10}$ Recriando o clima colonial opressivo dos estertores do ciclo aurífero, Autran lança âncoras aos dez anos do regime militar, trabalhando a temática da prisão, da tortura, da morte em efígie, enfim das relações de poder nos mais diversos níveis: senhor/escravo, homem/mulher, governante/governado, colônia/metrópole. Não se trata de um romance histórico, na acepção tradicional do termo, mas um texto historicizado, pronto a ser apropriado como história fantástica, isto é, alegoria que percorre em condensações e deslocamentos os períodos históricos caracterizados pela opressão individual e em todos os segmentos da sociedade.

O ciclo do fantástico no período de maior repressão se fecha com Fazenda modelo (1975) de Chico Buarque. Os animais comandados pelos homens em A bora dos ruminantes para oprimirem os simplórios moradores de Manarairema; os muros e os bichos espalhados pela CIA na cidade que esta assaltou; o companheiro porco e a companheira galinha, revolucionários às ordens do Capitão Birobidjan na colônia socialista de O exército de um homem só revestem-se, na novela pecuária Fazenda modelo, de uma roupagem opressora tecnicizada. Têmse agora animais humanizados/homens animalizados que recorrem à ciência e à tecnologia para inventarem uma nova sociedade. A fazenda em que se respirava

10. "Autran Dourado, escrevendo sobre a decadência do colonial (...) nos leva à leitura de outras crises da história do Brasil, referindo-se ambiguamente, por exemplo, à era de trinta, aos anos sessenta". (SENRA, Ângela Maria de Freitas. Paixão e fé: Os sinos da agonia de Autran Dourado.) 
liberdade e em que se preservava a natureza vê-se transformada subitamente por um Ato em verdadeiro campo de concentração, onde se fazem experiências para o aperfeiçoamento da espécie.

Juvenal, o boi-mor, o Justo, o Tenaz, é o novo Hitler a deliciar-se com experimentalismos tecnológicos e tecnocráticos em clima kafkiano, tendo como conselheiros jovens bois, cujos nomes se iniciam com K.

O texto de Buarque se abre com um Prefácio imaginário, assinado por K. Kleber, onde se lê que

As novas gerações estão com sua atenção voltada para os problemas da nossa Fazenda: estão participando do nosso desenvolvimento. O autor é um dos lídimos representantes dessa mentalidade nova que tanta confiança infunde no futuro da Fazenda Modelo. ${ }^{11}$

Prenuncia-se aí o discurso da nova ordem, do trabalho político de alienação e cooptação da juventude encurralada e obediente, cuja função é estudar "para se diplomar em boi-de-serviço". Assim a novela, transitando entre o alegórico grotesco e a sátira humorística, transmite o seu recado incensurável, como testemunho de uma fase histórica que colhia os frutos de um milagre econômico que não admitia contestações, onde a autocracia e o tecnocratismo caminhavam lado a lado. Fazenda modelo, superministério da Fazenda, modelo nazifascista de fazer novos cidadãos, concentrá-los em currais e estábulos, utilizá-los como cobaias das mais variadas experiências milagreiras.

Nesse mesmo ano de 1975 começa a surgir uma luz no fim do túnel, refletida em dois eventos: o ciclo de debates no Teatro Casa Grande, no Rio, o primeiro organizado em dez anos sem a interferência da polícia, e uma entrevista coletiva de escritores na revista Visão. No Teatro, durante a sessão sobre literatura, apresentou-se um balanço, ainda que tímido, sobre o que se fez e o que se deixou de fazer no período. Amoroso Lima escreveu sobre a luta entre o objetivo e o subjetivo na criação. Antônio Cândido ressaltou o caráter fragmentário desta e Antônio Callado assinalou a falta de público leitor em decorrência da falta de

\section{BUARQUE. Fazenda modelo, p. 15.}


incentivo criador. É claro que tais falas vinham no bojo de uma percepção crítica maior sobre o que rolava no cenário nacional, denunciando-o, ainda de forma tímida como disse, às mil e quatrocentas pessoas, na maioria jovens, que lotaram a casa de espetáculos. E sem ameaçar a ordem pública. ${ }^{12}$ Na revista Visão escritores arremetiam contra a precária difusão do livro nacional, o pequeno número de leitores e pediam a abolição da censura. ${ }^{13}$

Coincidência ou não, a partir de 1976 aparecem os primeiros textos em que as questões políticas são tratadas sem artifícios burladores. Tais textos vão desde Reflexos do baile, onde a fantasticidade perde para a construtividade fragmentada da narrativa e o trabalho com a linguagem alcança em Callado o mais elevado nível, até livros-depoimento do tipo Em câmara lenta, de Renato Tapajós e Ensaio geral, de Antonio Marcello, que referenciam a militância de esquerda esmagada pela repressão, textos estes de 77 e 78, respectivamente. É ainda de 1978 o maior número de ensaios de política e sociologia que o período conheceu.

Nos primeiros anos da década de 80 acabou-se a época obscurantista. Hoje, o menino de Incidente em Antares já não lê no muro Li-ber... como se fosse palavrão.

The novel under censorship

Abstract: This article discusses aspects of some Brazilian novels published during the 1964 regime in order to show that the fictional representation of sociopolitical issues did not lead to problems with censorship because the writers employed resources to deceive it.

Keywords: Brazilian novel, military dictatorship, censorship.

12. As sessões foram publicadas em Ciclo de debates do Teatro Casa Grande.

13. ESCRITORES desmentem crise de criatividade, p. 106-112. 


$$
\text { Referências }
$$

AMADO, Jorge. Dona Flor e seus dois maridos. São Paulo: Martins, 1966.

BUARQUE, Chico. Fazenda modelo. Rio de Janeiro: Civilização Brasileira, 1975.

CALlADO, Antônio. Bar Don Juan. Rio de Janeiro: Civilização Brasileira, 1972.

CHAVES, Flávio Loureiro. Érico Veríssimo: realismo e sociedade. Porto Alegre: Globo, 1976.

CICLO de debates do Teatro Casa Grande. Rio de Janeiro: Inúbia, 1976.

ESCRITORES desmentem crise de criatividade. Visão, São Paulo, p. 106-112, 10 nov. 1975 .

FONSECA, Maria Nazareth Soares. A relação bistória/estória em Incidente em Antares. Faculdade de Letras, 1980. (Dissertação de mestrado.)

FRESNOT, Daniel. O pensamento político de Érico Veríssimo. Rio de Janeiro: Graal, 1977.

MANDADO de segurança impetrado pela Editora Civilização Brasileira. Revista Civilização Brasileira, Rio de Janeiro, v.1, n.7, p. 411-14, maio, 1966.

PONTE PRETA, Stanislaw. O festival de besteira que assola o país. Rio de Janeiro: Ed. do Autor, 1966.

PROENÇA, M. Cavalcanti. A dissemântica de abril. Revista Civilização Brasileira, Rio de Janeiro, v. 1, n. 7, p. 10, maio, 1966.

SANTIAGO, Silviano. Repressão e censura no campo das artes na década de 70 . In: Vale quanto pesa. Rio de Janeiro/São Paulo: Paz e Terra, 1982.

SENRA, Ângela Maria de Freitas. Paixão e fé: Os sinos da agonia de Autran Dourado. Belo Horizonte, 1981. (Dissertação de mestrado.)

VERÍSSIMO, Érico. Incidente em Antares. Porto Alegre: Globo, 1972. 